\title{
Impacts of Global Warming on West African Monsoon Rainfall
}

\author{
Imoleayo E. Gbode, Vincent O. Ajayi, Kehinde O. Ogunjobi, \\ Jimy Dudhia, and Changhai Liu
}

\section{Contents}

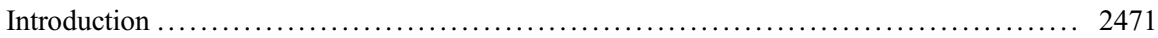

Model Domain, Data, and Methods ....................................... 2472

Model Domain and Numerical Experiment Setup ........................... 2472

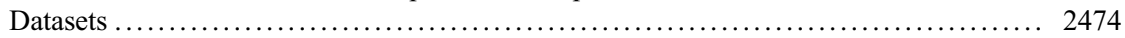

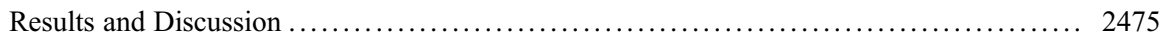

Temperature Characteristics .......................................... 2475

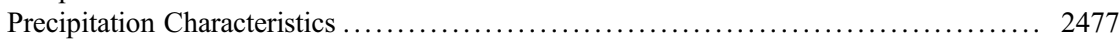

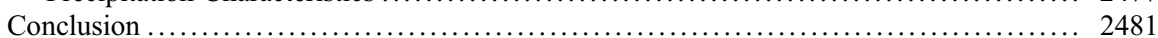

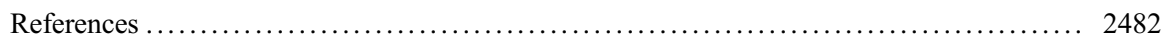

This chapter was previously published non-open access with exclusive rights reserved by the Publisher. It has been changed retrospectively to open access under a CC BY 4.0 license and the copyright holder is "The Author(s)". For further details, please see the license information at the end of the chapter.

I. E. Gbode $(\triangle)$

West African Science Service Center on Climate Change and Adapted Land Use, Federal University of Technology, Akure, Ondo State, Nigeria

Mesoscale and Microscale Meteorology Laboratory, National Center for Atmospheric Research, Foothills Laboratory, Boulder, CO, USA

e-mail: iegbode@futa.edu.ng

V. O. Ajayi

West African Science Service Center on Climate Change and Adapted Land Use,

Federal University of Technology, Akure, Ondo State, Nigeria

e-mail: voajayi@futa.edu.ng

K. O. Ogunjobi

Department of Meteorology and Climate Sciences, West African Science Service Centre on Climate Change and Adapted Land Use (WASCAL), Federal University of Technology Akure (FUTA), Ondo State, Nigeria

Federal University of Technology Akure (FUTA), Ondo State, Nigeria e-mail: ogunjobi.k@wascal.org 


\section{Abstract}

The impacts of global warming on rainfall in West Africa were examined using a numerical framework for 5 monsoon years (2001, 2007, 2008, 2010, and 2011). Rainfall characteristics over the three climatic zones, Guinea coast, Savannah, and Sahel, were analyzed. The potential changes associated with global warming were assessed by the pseudo-global warming (PGW) downscaling method. Multiple PGW runs were conducted using climate perturbation from the 40member ensemble of the Community Earth System Model version 1 (CESM1) coupled with Community Atmospheric Model version 5.2 (CAM5.2) component large ensemble project. The model output was compared with Tropical Rainfall Measuring Mission and Global Precipitation Climatology Project rainfall alongside surface temperature from the European Center for Medium-Range Weather Forecast Reanalysis. Results show that the estimated rainfall amount from the future climate in the 2070s increases slightly compared with the current climate. The total rainfall amount simulated for the current climate is $16 \%$ and $63 \%$ less than that of the PGW runs and observations, respectively. Also found is an increase (decrease) in heavy (light and moderate) rainfall amount in the PGW runs. These results are, however, contingent on the global circulation model (GCM), which provides the boundary conditions of the regional climate model. CESM1.0-CAM5.2, the GCM employed in this study, tends to provide a greater surface temperature change of about $4{ }^{\circ} \mathrm{C}$. This projected temperature change consequently caused the increase in the simulated precipitation in the PGW experiments, thus highlighting the advantage of using the PGW method to estimate the likely difference between the present and future climate with reduced large-scale model differences and computational resources. The findings of this study are, however, useful to inform decision-making in climate-related activities and guide the design of climate change adaptation projects for the West African region.

\section{Keywords}

Rainfall · Temperature - Pseudo-global warming - Guinea coast - Savannah · Sahel $\cdot$ Weather Research and Forecasting model $\cdot$ Community Earth System Model

\footnotetext{
J. Dudhia

Mesoscale and Microscale Meteorology Laboratory, National Center for Atmospheric Research, Foothills Laboratory, Boulder, CO, USA

e-mail: dudhia@ucar.edu

C. Liu

Research Applications Laboratory, National Center for Atmospheric Research,

Foothills Laboratory, Boulder, CO, USA

e-mail: chliu@ucar.edu
} 


\section{Introduction}

West African monsoon (WAM) prevails during the West African rainy season and provides a large amount of rainfall, over 75\% (Hagos and Cook 2007), in most parts of the region. Activities of the WAM vary across intraseasonal, interseasonal, and interannual time scale. This temporal variability is expected to intensify as a result of human-induced climate change which can thereafter cause serious consequences for health and human well-being, agriculture and food security, as well as water resources and hydrological cycles (Houghton et al. 2001; IPCC 2018).

Scientific researches have made tremendous efforts to improve the understanding of climate change and its causes, and these efforts are being advanced further to better understand the current and future potential impacts (CNR 2010; IPCC 2018). Climate models have proved useful to assess the current state of the climate and to project future climate conditions under various scenarios (NOAA 2019). Fully coupled global circulation models (GCMs) are useful tools for performing global simulations. These state-of-the-art models can be employed to investigate climate change associated with increase in greenhouse gas concentrations caused by anthropogenic activities. However, the coarse nature of GCM's horizontal resolution limits their ability to reproduce local climates, which are directly related to the inability of the model to properly resolve orographic features (IPCC 2007). Other methods such as statistical downscaling (Schmidli et al. 2006), dynamical downscaling (CORDEX, Giorgi et al. 2009), and direct simulation by high-resolution GCM (Wild et al. 1995) are gaining more application to project climate conditions at a regional scale. Therefore, to better represent climate phenomena of interest, in our case the West African monsoon, extremely high horizontal resolution is required. For example, a grid point interval of less than several kilometers or rather at a convection-permitting scale, usually less than $4 \mathrm{~km}$ (Prein et al. 2013), is more appropriate for simulating the complex interactions related to orography and local climate, which directly impact the monsoon system of the region.

Because the monsoon rainfall can vary at different time scales, long-term dynamical downscaling, such as the CORDEX, or ensemble projects are necessary to determine the impacts of global warming on the monsoon variability. Long-term simulations at several tens of kilometers or even convection-permitting grid is, however, rather difficult to obtain because of insufficient computational resources and high cost of the use of available resources. Considering the current constraint, to avoid huge computations as regards simulating a longer year-to-year variability, short period numerical experiments are done using the pseudo-global warming method.

The pseudo-global warming (PGW) approach (Liu et al. 2017) is a dynamic downscaling method that permits regional climate change projections with the use of a regional climate model. The PGW method employs initial and lateral boundary conditions that combine 6-hourly reanalysis data and the climate change signals, which are the monthly averaged differences between the current and future climate projections produced by a GCM. The method expects the boundary condition mean state to have similar climatology to those of the GCM future climate projections, but the daily evolution is similar to that of current years. The PGW technique provides the 
possibility of having a direct comparison between the present year and the PGW year in the context of the interannual variation with the addition of future climatology.

The objective of this research is to investigate the impacts of global warming on rainfall in West Africa during the monsoon period. We employed the PGW method to directly compare future rainfall amount with that of the current. The remaining part of the study is structured as follows: section "Model Domain, Data, and Methods" describes the study area and numerical experiment setup as well as the observation and reanalysis data used. Results and discussion are presented in section "Results and Discussion" and the conclusion is drawn in section "Conclusion."

\section{Model Domain, Data, and Methods}

\section{Model Domain and Numerical Experiment Setup}

The WRF model version 3.8.1 model is used to perform the regional climate simulations over a $20-\mathrm{km}$ horizontal resolution and 50 model levels. Similar to the studies of Gbode et al. (2019a, b), the domain covers the West African region $\left(0^{\circ}-20^{\circ} \mathrm{N}, 20^{\circ} \mathrm{W}-20^{\circ} \mathrm{E}\right.$; see Fig. 1), including parts of the Atlantic Ocean, that provides the most moisture carried into the region by the low-level monsoon flow.

Five years were selectively simulated and analyzed to account for interannual variability. The considered years represent wet (2008 and 2010), dry (2001 and 2011), and normal (2007) WAM years. The characteristics of the chosen years are determined by the departure of the total annual rainfall amount from long-term mean total annual rainfall over the entire West African domain (not shown for brevity).

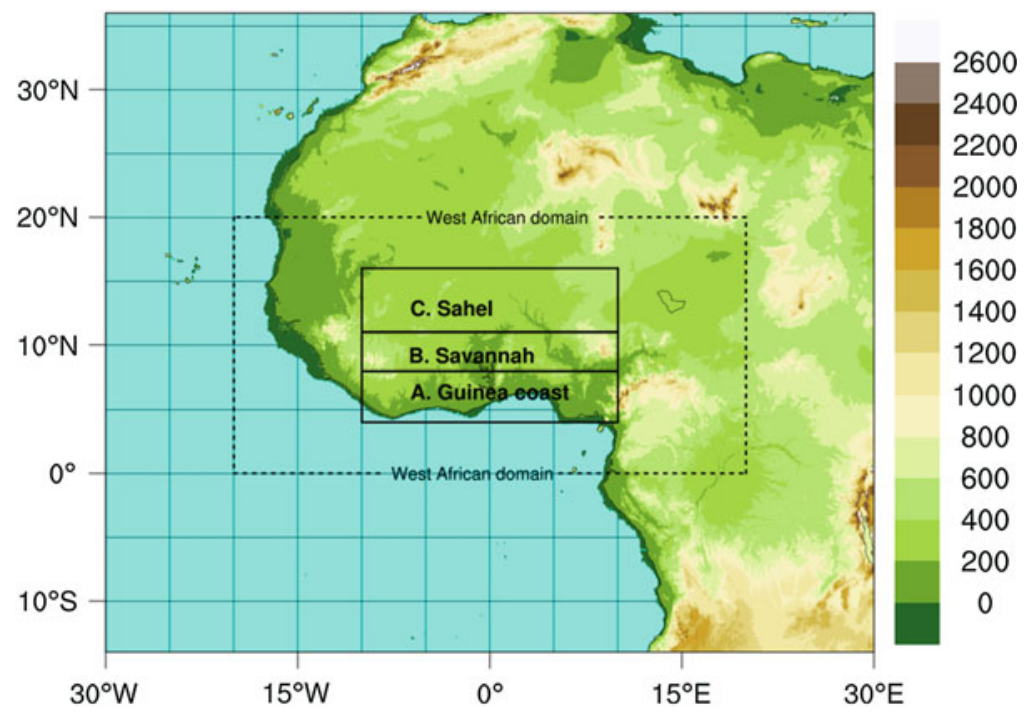

Fig. 1 WRF model domain showing elevation in meters and highlights of the West African $\left(0^{\circ}-20^{\circ} \mathrm{N}, 20^{\circ} \mathrm{W}-20^{\circ} \mathrm{E}\right)$ region and the three climatic zones: (a) Guinea coast, (b) Savannah, and (c) Sahel. (Source: Gbode et al. 2019b) 
The numerical study includes three experiments each for current climate and PGW simulations. These experiments combine different WRF model physics: two microphysics (MP), Goddard (GD) and Weather Research and Forecasting (WRF) model single-moment 5-class (WSM5); three planetary boundary layers (PBL), Mellor-Yamada-Janjić (MYJ), Mellor-Yamada-Nakanishi-Niino (MYNN) Level 2.5, and Yonsei University (YSU); and three cumulus convection (CU), BettMiller-Janjić (BMJ), new Tiedtke (nTDK), and new simplified Arakawa Schubert (nSAS) parameterization schemes. The choice of the selected combinations is based on results from a preliminary study (Gbode et al. 2019a).

The first experiment was a retrospective simulation aimed at reproducing the variability and mean state of the current climate within the model domain of $\sim 20 \mathrm{~km}$. The simulation contains the selected years, each extending from February to December, but the period March 1 to October 31 was analyzed. The present climate runs are hindcast runs driven by 6-hourly ERA-Interim (ERAI, Dee et al. 2011) atmospheric data with soil (moisture and temperature) initialization from the National Centers for Environmental Prediction Final Reanalysis (NCEP-FNL 2000) (Eq. 1). The NCEP FNL soil data was used to be consistent with the unified Noah land surface model, which was kept constant, as described in Gbode et al. (2019a).

$$
W R F_{\text {Input } 1}=\text { ERAInterim }_{\text {Atmosphere }}+F N L_{\text {Soil }}
$$

The second simulation closely follows the pseudo-global warming (PGW) approach used in previous studies (e.g., Liu et al. 2017). Though the approach doesn't account for extreme events, it, however, allows direct comparison between the current and future climate. The simulations of each of the selected years were forced with ERA-Interim, FNL reanalysis, plus climate perturbation (see Eq. 2) derived from the Community Earth System Model version 1 (CESMv1) with the Community Atmospheric Model version 5.2 (CAMv5.2) of the Large Ensemble Community Project (LENS) (Kay et al. 2015):

$$
\begin{aligned}
W R F_{\text {Input2 }}= & \text { ERAInterim }_{\text {Atmosphere }}+F N L_{\text {Soil }} \\
& +\overline{\Delta C E S M 1 \_C A M 5.2_{R C P 8.5}} \text { monthly }
\end{aligned}
$$

where $\overline{\Delta C E S M 1 \_C A M 5.2_{R C P 8.5}}{ }^{\text {monthly }}$ (see Eq. 3 ) is the monthly 30 -year LENS 40 member ensemble-mean change signal of the business as usual representative concentration pathway (RCP8.5), a comparatively high greenhouse gas emission pathway (Riahi et al. 2011):

$$
\begin{aligned}
{\overline{\Delta C E S M 1 \_C A M 5.2_{R C P 8.5}}}^{\text {monthly }}= & \overline{\text { CESM1_CAM5.2 2071-2100 }} \\
& -\overline{C E S M 1 \_C A M 5.21976-2005}
\end{aligned}
$$

The perturbed physical fields include horizontal wind, temperature, and relative humidity. First, the climate change signals are obtained at monthly average resolution, and then these are interpolated to analysis times and the model grid 
Table 1 Model greenhouse gas concentration to reflect the midyear value of the current (1976-2005) and future (2071-2100) simulations (IPCC 2007, 2014)

\begin{tabular}{l|l|l}
\hline Greenhouse gas & Current & Future (RCP8.5) \\
\hline Carbon dioxide $\left(\mathrm{CO}_{2}\right)$ & $379 \mathrm{ppmv}$ & $801 \mathrm{ppmv}$ \\
\hline Methane $\left(\mathrm{CH}_{4}\right)$ & $1774 \mathrm{ppbv}$ & $3564 \mathrm{ppbv}$ \\
\hline Nitrous oxide $\left(\mathrm{N}_{2} \mathrm{O}\right)$ & $319 \mathrm{ppbv}$ & $414 \mathrm{ppbv}$ \\
\hline Chlorofluorocarbons-11(CFC-11) & $251 \mathrm{ppt}$ & $86 \mathrm{ppt}$ \\
\hline Chlorofluorocarbons-12(CFC-12) & $538 \mathrm{ppt}$ & $211 \mathrm{ppt}$ \\
\hline
\end{tabular}

when adding them to the analyses. The LENS CESMv1-CAMv5.2 is approximately $1^{\circ}$ latitude/longitude with CAMv5.2 as its atmospheric component. CESMv1-CAMv5.2 is a 40-member ensemble of the LENS of fully coupled CESMv1 simulations for the current (historical) and future (RCP8.5) periods 1976-2005 and 2071-2100, respectively. Each member is subjected to the same radiative forcing scenario but begins from a slightly different initial atmospheric state created by randomly perturbing temperatures at the level of round-off error (Kay et al. 2015). The ensemble average is used to remove interannual variability from the climate change signal.

Before running the PGW simulations, the WRF model was recompiled to reflect the expected mean greenhouse gas concentration levels of the midyear of the last climate epoch of the twenty-first century (i.e., 2086) for the representative concentration pathway 8.5 (see Table 1; IPCC 2007, 2014). RCP8.5, a greenhouse gas concentration (not emissions) trajectory, is one of the four RCPs IPCC adopted in its fifth Assessment Report (AR5). The RCP 8.5 is categorized based on possible radiative forcing value of $8.5 \mathrm{~W} / \mathrm{m}^{2}$, which assumes that emissions will continue to rise throughout the twenty-first century (Meinshausen et al. 2011).

\section{Datasets}

The absence of a richly dense network of conventional rain gauges and synoptic weather stations limits the model validation to satellite rainfall products (SRPs) and reanalysis datasets. For rainfall, Tropical Rainfall Measuring Mission (TRMM) (Huffman et al. 2007) and GPCP (Huffman et al. 2016) are used. Though the satellite-derived rainfall contains differences consequent to their observation platforms and different algorithms used in producing them, they, however, conserve the mean rainfall features (Sylla et al. 2013). The Global Precipitation Climatology Project $1^{\circ}$ Daily (GPCP 1dd) is a reliable SRP produced from optimized merged estimates computed from microwave, infrared, and sounder data observed by the international constellation of precipitation-related satellites and precipitation gauge analysis (Huffman et al. 2016). Also, the daily TRMM 3B42 version 7 is another reliable source for merged high-quality precipitation estimates (Huffman et al. 2007). The model rainfall is compared with both GPCP and TRMM and its surface air temperature against reanalysis data from the European Center for Medium-Range Weather Forecast Reanalysis (ERAI). 


\section{Results and Discussion}

\section{Temperature Characteristics}

Figure 2 shows the mean surface air temperature averaged during the period JJAS for ERAI reanalysis and model outputs (i.e., present and future runs). In this panel, Fig. 2a, b shows the current and future runs from CESM, Fig. 2c depicts ERAI, Fig. 2d, f shows the present climate runs, Fig. 2g, i shows the PGW runs, and Fig. 2j, 1 depicts the difference between PGW and present climate during JJAS. The boxplot below Fig. 2c shows the statistics of the 2-meter temperature from March to October over the area within latitudes $5-15^{\circ} \mathrm{N}$ and longitudes $10^{\circ} \mathrm{W}-10^{\circ} \mathrm{E}$.

The reanalysis shows observed temperature range between $20^{\circ} \mathrm{C}$ and $36{ }^{\circ} \mathrm{C}$ with a steep gradient in the Sahel. This gradient is associated with the Saharan heat low defined by the mean position of the intertropical discontinuity (ITD) and lowpressure center, mostly in August when the monsoon is fully developed (Nicholson 2013). Also, surface air temperature over complex orographic terrains is cooler relative to the desert and nearby land areas. During the twentieth century (Fig. 2a), CESM simulates similar distribution as observed but cooler temperatures over complex terrains, mostly over the Cameroon Mountains and Fouta Djallon highlands. In the future runs (Fig. 2b), the model simulates warmer conditions over the complex terrains and even higher temperatures of about $40{ }^{\circ} \mathrm{C}$ over the Sahel. The present runs from the WRF model (Fig. 2d, f) also agree with the reanalyzed temperature gradient but with some biases mostly in the Sahara desert region. Simulated air temperature in the PGW runs, generally, shows warming across the entire domain and ocean (Fig. $2 \mathrm{~g}-\mathrm{i}$ ). The maximum value exceeds $40{ }^{\circ} \mathrm{C}$ over the desert area. Relative to the present climate, the PGW runs are $5{ }^{\circ} \mathrm{C}$ warmer. In GDMYJ-BMJ8.5 and WSM5-YSU-nSAS8.5, there is a uniform warming of $4{ }^{\circ} \mathrm{C}$ from the coast upward to about $15^{\circ} \mathrm{N}$ latitude followed by a northward steep gradient. A similar warming pattern is found in WSM5-MYNN-nTDK8.5 but restricted only to about $10^{\circ} \mathrm{N}$. Over the ocean, the magnitude of warming is lesser perhaps due to its high heat retention capacity.

The box-percentile plot below Fig. 2c presents the distribution of temperature values during the period March to October for the area enclosed within latitudes $5^{\circ}-15^{\circ} \mathrm{N}$ and longitudes $10^{\circ} \mathrm{W}-10^{\circ} \mathrm{E}$. The values of ERAI range between $25^{\circ} \mathrm{C}$ and $31{ }^{\circ} \mathrm{C}$ with the mean being $27.9^{\circ} \mathrm{C}$. The distribution of the current climate simulation ranges from $24{ }^{\circ} \mathrm{C}$ to $31.5{ }^{\circ} \mathrm{C}$. Relative to the WRF simulations, CESM simulates lower temperatures during the current and future runs. Results of the PGW runs show a wider range of temperature $\left(28-36^{\circ} \mathrm{C}\right)$ and a significant shift in the mean. The average difference in the mean between the PGW and current is approximately $4{ }^{\circ} \mathrm{C}$. The warming is generally found in all three simulations.

Further analysis of the probability distribution shows that the surface air temperature averaged over $0-20^{\circ} \mathrm{N}$ and $20^{\circ} \mathrm{W}-20^{\circ} \mathrm{E}$ varies from $24^{\circ} \mathrm{C}$ to $31^{\circ} \mathrm{C}$ and from $27{ }^{\circ} \mathrm{C}$ to $35.3{ }^{\circ} \mathrm{C}$ for the current and future climate, respectively, with two density maxima that are related to stronger peaks in some months (Fig. 3). These density maxima could be associated with pre-monsoon, when the temperatures are 

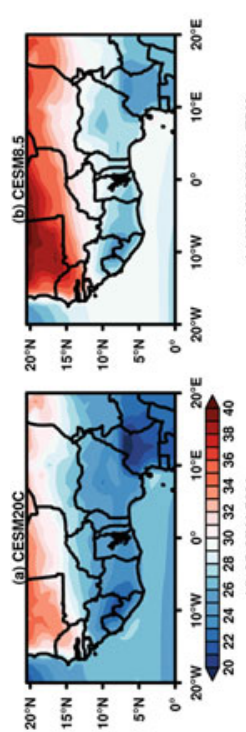
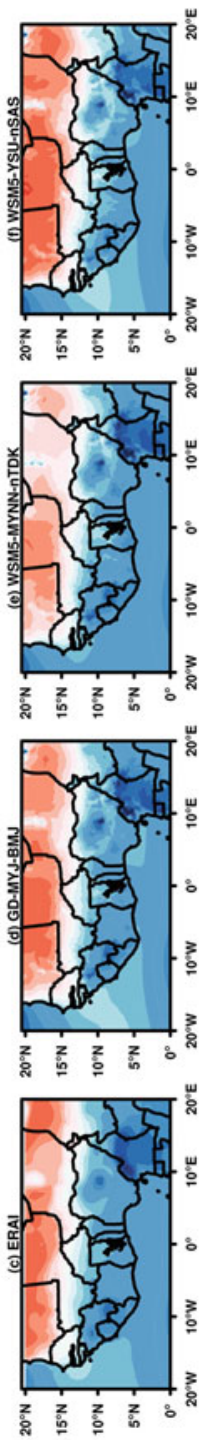
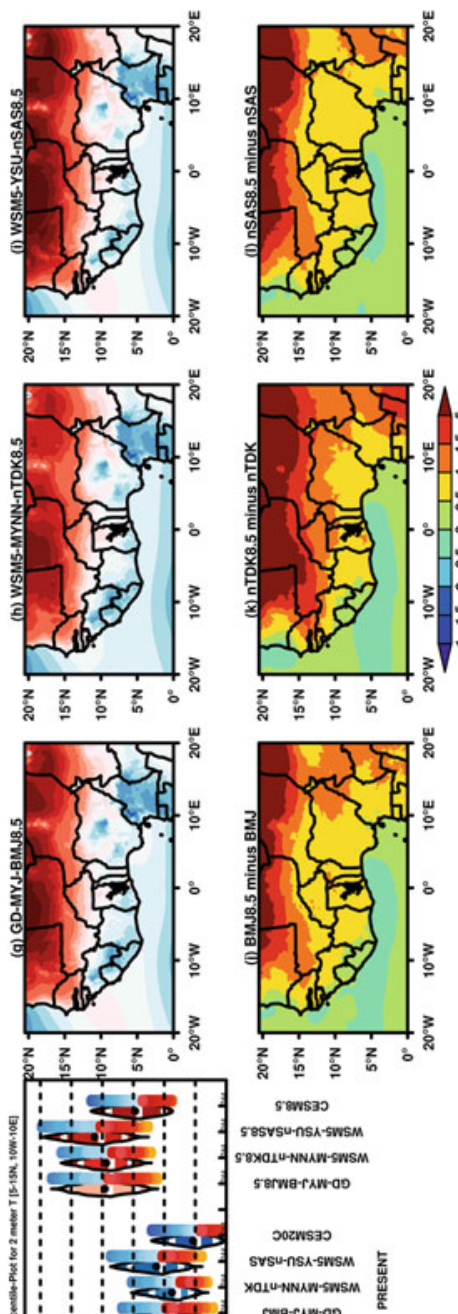

เพมง

월

क

อิ ติ

表苛

तै ${ }^{\pi}>$

తิ

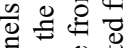

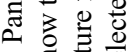

的武

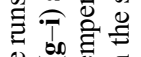

舟

寻寻早

芩

矛苛它

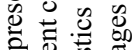

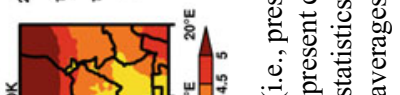

可焉

苛导

है के है

क्षे के

I 0 它

式过要

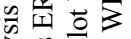

츨 을

ङ 웡.

¿巳巳

的元

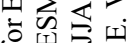

我 000

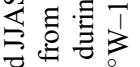

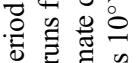

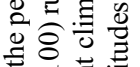

에규

흘형음

월 छ

带总证

卷 छิ

光全总

迅氞 矛

范

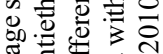

एँ

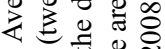

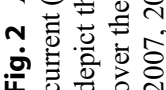


Mean Temperature $\left({ }^{\circ} \mathrm{C}\right)$ PDF averaged over $0-20^{\circ} \mathrm{N}$ and $20^{\circ} \mathrm{W}-20^{\circ} \mathrm{E}$

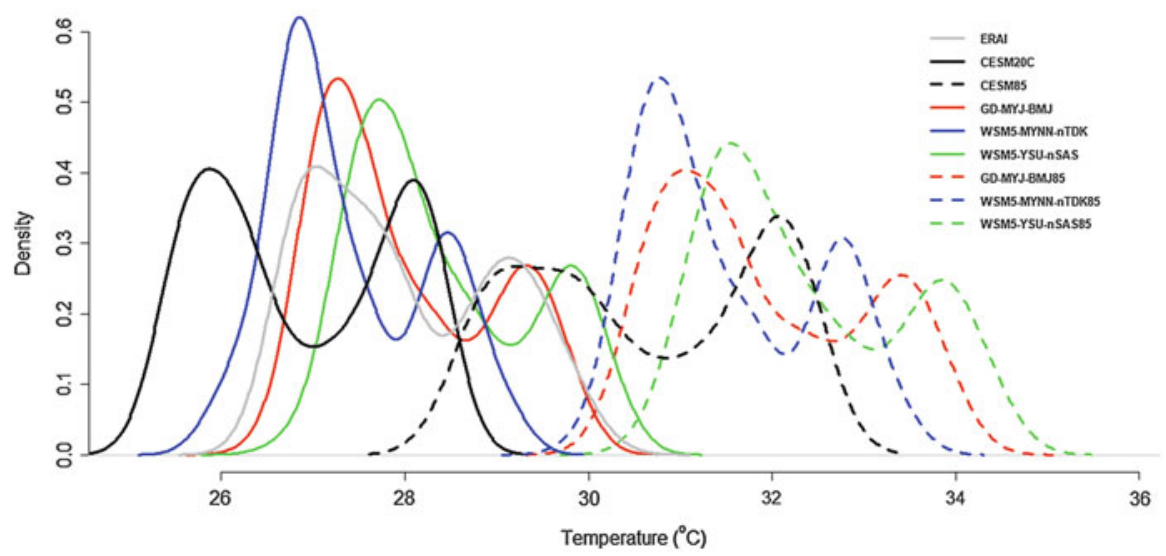

Fig. 3 Probability density function of observed and simulated daily mean temperature averaged over $0-20^{\circ} \mathrm{N}$ and $20^{\circ} \mathrm{W}-20^{\circ} \mathrm{E}$ domain. ERAI and WRF outputs are derived from the average of the selected five years, while CESM20C and CESM85 are derived for the period 1976-2005 (continuous lines) and 2071-2100 (dash lines), respectively

usually high as a result of clear sky conditions that allow more insolation to reach the surface, and post-monsoon periods, when the temperatures are usually low as a result of frequent convective activities that bring about cloudy conditions which prevent incoming radiation from reaching the surface. The observed density (gray line, i.e., ERAI) corresponding to the low (high) temperature maxima is higher (lower). CEMS simulates lower temperatures compared with ERAI and WRF current and PGW runs. This underscores the benefit of having a high-resolution regional climate simulation. The three model experiments also reproduced the observed distribution with varying densities. For example, the density of low temperature values in WSM5-MYNN-nTDK is higher compared with that of GD-MYJ-BMJ and WSM5-YSU-nSAS. During the last climate regime of the twenty-first century (2071-2100), both GCM and RCMs simulate a significant increase in temperature. Temperatures in the WRF runs are expected to increase more compared with the GCM. The upper bound shift in temperature could reach $3-4{ }^{\circ} \mathrm{C}$.

\section{Precipitation Characteristics}

The observed average daily precipitation amount and the modeled values for present and future simulations during the period June-September (JJAS) are presented in Fig. 4. Also, the bottom boxplot of Fig. 4 shows the statistics of the daily precipitation distribution from March to October over the area bounded by latitudes $5-15^{\circ} \mathrm{N}$ and longitudes $10^{\circ} \mathrm{W}-10^{\circ} \mathrm{E}$. GPCP and TRMM (in Fig. 4a, b) show average daily rainfall values reaching 14 and $16 \mathrm{~mm}$ day $^{-1}$, respectively. Both observed products agree in terms of producing maximum values over complex orographic terrains and 


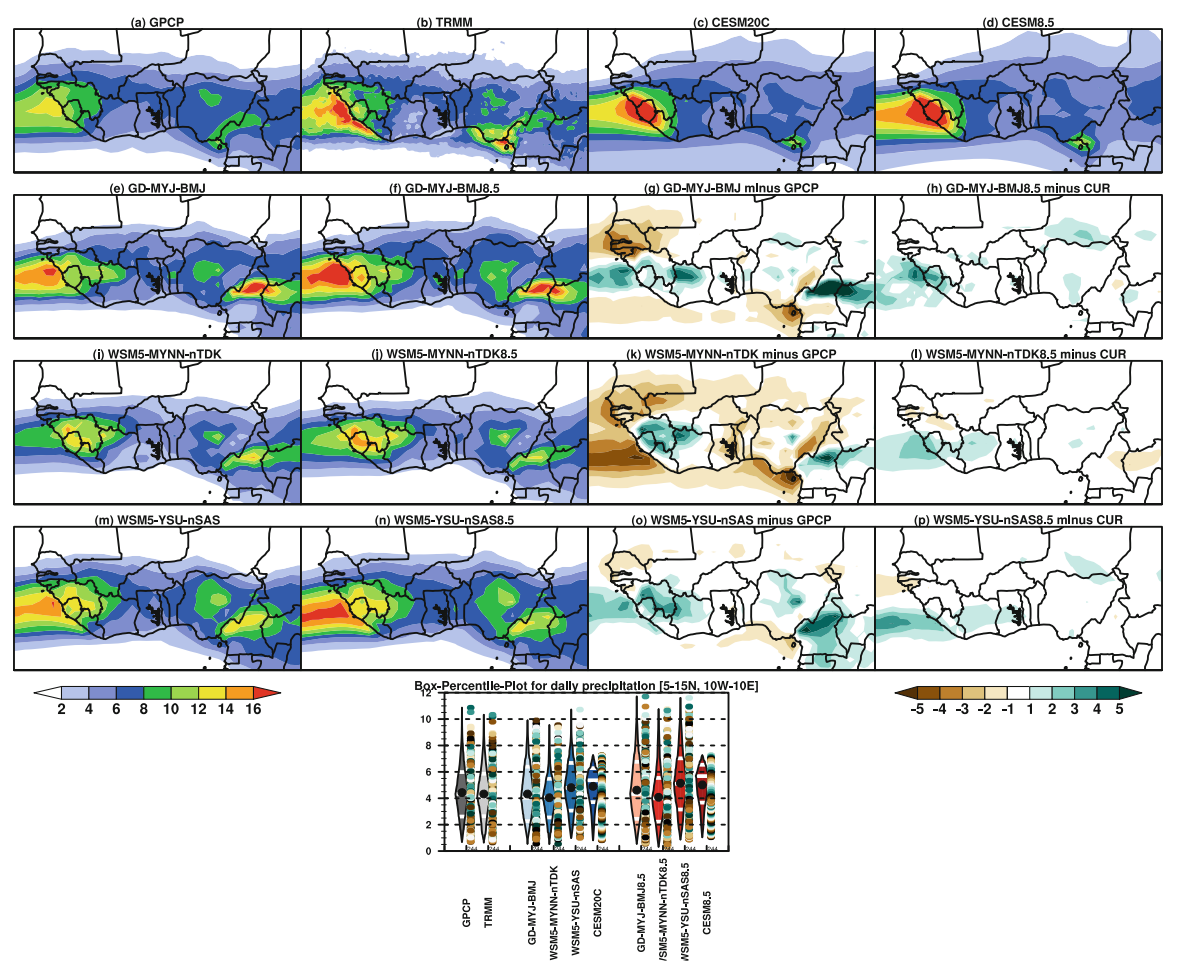

Fig. 4 Spatial distribution of average daily rainfall $\left(\mathrm{mm} \mathrm{day}^{-1}\right)$ for the period JJAS. Values of (a) GPCP, (b) TRMM, and (e, $\mathbf{f}, \mathbf{i}, \mathbf{j}, \mathbf{m}$, and $\mathbf{n}$ ) WRF runs are derived from the average of the five simulated years, while (c and d) CESM values are derived from the considered 30-year current and future periods. Differences between (g, $\mathbf{k}$, and $\mathbf{o})$ GPCP and WRF current and (h, l, and p) PGW and current runs are also presented in the figure. The bottom boxplot shows the statistics of the daily precipitation distribution from March to October over the area of latitudes $5-15^{\circ} \mathrm{N}$ and longitudes $10^{\circ} \mathrm{W}-10{ }^{\circ} \mathrm{E}$

minimum in other land areas. CESM simulates values of $16 \mathrm{~mm} \mathrm{day}^{-1}$ in the twentieth century and RCP8.5 (Fig. 4c, d) in agreement with TRMM, but the GCM, however, shows deficiencies in reproducing the observed maximum over complex terrains of Jos Plateau and the southeast orientation pattern over the Cameroon Mountains; this points out the limitations of the GCM to reproduce certain features due to its coarse horizontal resolution that makes it difficult to properly capture atmospheric phenomena at smaller horizontal scales than its grid.

Consistent in observations and WRF simulations is the band of maximum daily average rainfall sitting, on average, along latitude $10^{\circ} \mathrm{N}$. Also, the RCM runs agree with observations as they simulate the climatological precipitation maxima over complex orographic terrains of Cameroon Mountains, Jos Plateau, and Fouta Djallon highlands with extension toward the western coast of West Africa. In the present year simulations, GD-MYJ-BMJ also reproduces the magnitude of $16 \mathrm{~mm}^{\text {day }}{ }^{-1}$ over the Cameroon Mountain and the west coast of the monsoon region (Fig. 4e). For 
WSM5-MYNN-nTDK and WSM5-YSU-nSAS (Fig. 4i, m) runs, the simulated magnitude could be $15 \mathrm{~mm}$ day $^{-1}$ or less. The PGW runs show an increase in daily precipitation relative to the present climate runs, most especially over complex orographic terrains and over the west coast of West Africa. While the simulated values of GD-MYJ-BMJ8.5 and WSM5-YSU-nSAS8.5 could be greater than $17 \mathrm{~mm}$ day $^{-1}$, that of WSM5-MYNN-nTDK8.5 only simulates maximum of $15 \mathrm{~mm} \mathrm{day}^{-1}$ (Fig. 4f, j, and n).

Although the models agree with the observation patterns, there exist some systematic errors. The degree of these errors is quantitatively assessed, firstly, by taking the difference between current runs and GPCP (Fig. 4g, k, and o). The results show wetness of about $5 \mathrm{~mm}$ day $^{-1}$ over complex terrain and other land areas. In contrast, dryness (less than $-5 \mathrm{~mm}^{\text {day }}{ }^{-1}$ ) is simulated over the western Sahel and along the southern coast of the monsoon region as well as ocean areas. Secondly, the degree of error is quantitatively assessed by computing the difference between PGW and current climate runs which shows general wetness of less than $4 \mathrm{~mm}$ day $^{-1}$ around the western part of the region and small extent of $2 \mathrm{~mm}$ day $^{-1}$ dryness in other land areas (Fig. 4h, 1, and p). Further, to examine the effect of warming on precipitation, the statistics of observations and model results are presented at the bottom of Fig. 4 (boxplot). Results show that the maximum observed and modeled daily precipitation in the considered area $\left(5^{\circ}-15^{\circ} \mathrm{N}\right.$ and $\left.10^{\circ} \mathrm{W}-10^{\circ} \mathrm{E}\right)$ is about 11 and $12 \mathrm{~mm} \mathrm{day}^{-1}$ for PGW runs. In CESM, the values are less than $8 \mathrm{~mm} \mathrm{day}^{-1}$. The mean value for GPCP and TRMM is slightly above $4 \mathrm{~mm} \mathrm{day}^{-1}$. For the current climate runs, GD-MYJ-BMJ agrees with the observed mean values, while WSM5MYNN-nTDK simulates exactly $4 \mathrm{~mm}^{\text {day }}{ }^{-1}$. WSM5-YSU-nSAS produces higher magnitudes of daily precipitation and an increase in the mean (i.e., $5 \mathrm{~mm} \mathrm{day}^{-1}$ ). The impacts of warming are evident through an increase in the mean and maximum value of PGW runs. This response is most obvious in GD-MYJ-BMJ8.5 and WSM5-YSUnSAS8.5, where there is a slight increase in the mean $\left(\sim 0.2 \mathrm{~mm} \mathrm{day}^{-1}\right)$ and maximum daily rainfall $\left(>12 \mathrm{~mm} \mathrm{day}^{-1}\right)$. In WSM5-MYNN-nTDK, there is an increase in the maximum daily precipitation values but no significant change in the mean distribution.

The precipitation changes (shown in Fig. 2) between GPCP and current runs are averagely found to be $-5,0.6$, and $-50 \%$ in the Guinea coast, Savannah, and Sahel, respectively. Also, differences between TRMM and current runs may reach maximum values of $-19,-7$, and $-52 \%$ for the corresponding climatic zones. Some of the models underestimate the observed average daily rainfall, mostly in TRMM. Between the current and PGW runs, the average percentage difference is generally small and ranges between $-2 \%$ and $16 \%$ over the entire monsoon region. In general, the average percentage difference is greater mostly in the Sahel. This suggests the possibility of experiencing greater impacts on rainfall regimes in the Sahel as a result of global warming. Relative to Sahel, a less impact is felt in the Guinea coast, where there are heterogeneous surfaces and features, and a mild influence in Savannah (Table 2).

Furthermore, the probability distribution analysis of the average daily rainfall amount reveals varying densities over the $5-15^{\circ} \mathrm{N}$ latitudes and $10^{\circ} \mathrm{W}-10^{\circ} \mathrm{E}$ 
Table 2 Average percentage difference (\%) of total rainfall amount observed and modeled during the period March to October for the five years over each climatic zone. GPCP and TRMM (upper row) are subtracted from the current model runs (lower rows) to compute the percentage difference. In the same manner, the current runs are subtracted from the PGW runs

\begin{tabular}{l|l|l|l|l|l|l|l|l|l}
\hline & \multicolumn{3}{l}{ GPCP } & \multicolumn{2}{l|}{ TRMM } & \multicolumn{2}{l}{ PRESENT } \\
\cline { 2 - 11 } Climatic zone & BMJ & nTDK & nSAS & BMJ & nTDK & nSAS & BMJ8.5 & nTDK8.5 & nSAS8.5 \\
\hline Guinea coast & -12 & -10 & 7 & -3 & -18 & -19 & 3 & -1 & 8 \\
\hline Savannah & 1 & -6 & 7 & -3 & -6 & -12 & 3 & 4 & 6 \\
\hline Sahel & -47 & -59 & -45 & -50 & -44 & -63 & 16 & -2 & 9 \\
\hline
\end{tabular}

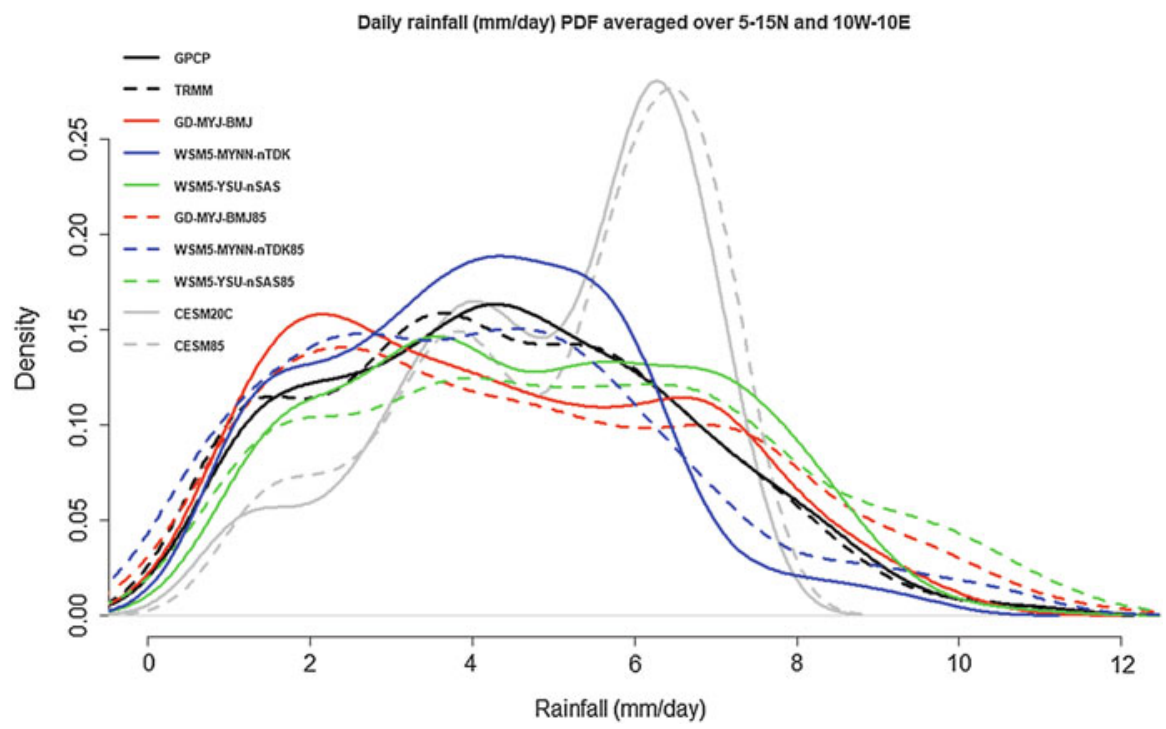

Fig. 5 Probability density function of observed and simulated daily mean rainfall averaged over the $5-15^{\circ} \mathrm{N}$ and $10^{\circ} \mathrm{W}-10^{\circ} \mathrm{E}$ domain. GPCP, TRMM, and WRF outputs are derived from the average of the selected five years, while CESM20C and CESM85 are derived for the periods 19762005 and 2071-2100, respectively

longitudes (as shown in Fig. 5). The rainfall distribution between GPCP and TRMM is similar with little differences. Both the current and future climate runs of CESM possess a high density of rainfall of about $6 \mathrm{~mm}^{\text {day }}{ }^{-1}$. Also, a slight rainfall increase of greater than $6 \mathrm{~mm} \mathrm{day}^{-1}$ is simulated in CESM future runs relative to the current runs. Whereas values of less than $6 \mathrm{~mm} \mathrm{day}^{-1}$, however, occur more in the GCM's current runs. The distribution in the WRF simulations is similar to that of the observations, thus highlighting the benefit of having high-resolution regional climate simulations. Generally, the WRF model simulates occurrences of increased heavy and light rainfall in the PGW runs. Also, the PGW run simulates lesser frequencies of moderate rains. WSM5-YSU-nSAS PGW runs simulate higher average daily rainfall intensity relative to WSM5-MYNN-nTDK and GD-MYJ-BMJ, 
respectively. This combination, however, simulates lower densities of moderate average daily rainfall.

To further investigate the characteristics of daily rainfall over the region, the rainfall is disintegrated into different categories, light $\left(1-2 \mathrm{~mm} \mathrm{day}^{-1}\right)$, moderate $\left(\geq 2-10 \mathrm{~mm} \mathrm{day}^{-1}\right)$, and heavy $\left(\geq 10 \mathrm{~mm}^{\text {day }}{ }^{-1}\right)$, based on the probability density function presented in Fig. 5. Rainfall between 1 and $2 \mathrm{~mm}$ provides percentage of rainfall within the range of 7.7-8.7\% for the period March to October (not shown for brevity) and decreases by $0.8-1 \%$ in the RCM. Category of rainfall within $2-10 \mathrm{~mm}$ provides $54-67 \%$ of rainfall and shows not only a decrease in the frequency of rains but also a decrease in the percentage (i.e., $3-6 \%$ ) in the future. Heavy rainfall (i.e. 10 $\mathrm{mm}$ and above) contributes between $24-31.4 \%$ and $30-37.9 \%$ rainfall amount in the current and future climate, respectively, in WRF simulations. This type of rainfall is expected to increase by $3-6.5 \%$ in the future. For CESM, the percentage of $42.2 \%$ and $49.4 \%$ is simulated in the current and future climate, respectively. The GCM simulates this feature only in the complex terrain of Cameroon Mountains and the west coast of the monsoon region.

Though the results of this study are based on the GCM, which provides the boundary conditions for the RCM, it provides useful insights to inform decisionmaking in climate-related sectors of the economy such as agriculture, water resources, hydropower generation, and other climate-dependent activities. Likewise, the findings are useful to guide the design of climate change adaptation projects that will ensure a climate-resilient and sustainable development. The PGW approach used, however, doesn't account for extreme events. Hence, the need for longer-term simulations in future studies to assess extreme events and their associated impacts.

\section{Conclusion}

This study examined the impacts of global warming on precipitation amount during the West African monsoon season using the PGW method. Three experiments that combine microphysics, convection, and planetary boundary layer parameterization schemes were also conducted for both current and PGW climate runs. Model runs were performed for selected wet (2008-2010), dry (2001-2011), and normal (2007) monsoon years in the region at $20-\mathrm{km}$ horizontal resolution. Also, the precipitation characteristics over the three climatic zones; Guinea coast, Savannah, and Sahel, were analyzed. The current and PGW climate runs showed good agreement with the observed precipitation by reproducing the spatial distribution pattern over complex orographic terrains. The estimated rainfall amount in the 2070s from the PGW runs increased slightly compared with the current climate runs. In all climatic zones, the total precipitation amount simulated by the current climate is less than $16 \%$ and $63 \%$ relative to the PGW runs and the observations, respectively. However, the difference between current climate runs and observations is higher relative to that of PGW runs. GD-MYJ-BMJ runs have good agreement with observations in terms of simulating the characteristics of wet, dry, and normal monsoon years, which is defined by total precipitation amount. WSM5-MYNN-nTDK is more consistent in defining the 
precipitation characteristic in Savannah and Sahel, while WSM5-YSU-nSAS rarely agrees in any two of the climatic zones. Also found is an increase in heavy rainfall amount and a decrease in both light and moderate rainfall amount.

Though the results of this study are based on the GCM, which provides the boundary conditions for the RCM, it provides useful insights to guide policymakers to make informed decisions on issues concerning climate-related sectors of the economy such as agriculture, water resources, hydropower generation, and other climate-dependent activities. Besides, the findings are useful to guide the design of climate change adaptation projects that will ensure a climate-resilient and sustainable development. The PGW approach used, however, doesn't account for extreme events, hence, the need for longer simulations in future studies.

Acknowledgments The German Federal Ministry of Education and Research (BMBF) primarily funded this research through the Doctoral Research Programme-West African Climate System (DRP-WACS) hosted at the Federal University of Technology Akure (FUTA), Ondo State, Nigeria. Many thanks to NCAR's MMM Laboratory for supporting the research work. We would like to acknowledge highperformance computing support from Cheyenne (https://doi.org/10.5065/ D6RX99HX) provided by NCAR's Computational and Information Systems Laboratory, sponsored by the National Science Foundation.

\section{References}

Council National Research (2010) Advancing the science of climate change. The National Academies Press, Washington, DC. https://doi.org/10.17226/12782

Dee DP, Uppala SM, Simmons AJ, Berrisford P, Poli P, Kobayashi S et al (2011) The ERA-interim reanalysis: configuration and performance of the data assimilation system. Q J R Meteorol Soc 137:553-597. https://doi.org/10.1002/qj.828

Gbode IE, Dudhia J, Ogunjobi KO, Ajayi VO (2019a) Sensitivity of different physics schemes in the WRF model during a West African monsoon regime. Theor Appl Climatol 136(1-2):733751. https://doi.org/10.1007/s00704-018-2538-x

Gbode IE, Ogunjobi KO, Dudhia J, Ajayi VO (2019b) Simulation of wet and dry West African monsoon rainfall seasons using the Weather Research and Forecasting model. Theor Appl Climatol 1-16. https://doi.org/10.1007/s00704-019-02912-x

Giorgi F, Jones C, Asrar GR (2009) Addressing climate information needs at the regional level: the CORDEX framework. Bull World Meteorol Organ 58(3):175-183

Hagos SM, Cook KH (2007) Dynamics of the West African monsoon jump. J Clim 20(21):52645284. https://doi.org/10.1175/2007JCLI1533.1

Houghton JT, Ding Y, Griggs DJ, Noguer M, van der Linden PJ, Dai X, Maskell K, Johnson C (2001) Climate change 2001: the scientific basis, 881. https://doi.org/10.1256/ 004316502320517344

Huffman GJ, Bolvin DT, Adler RF (2016) GPCP version 1.2 one- degree daily precipitation data set. Research data archive at the National Center for Atmospheric Research, Computational And Information Systems Laboratory. https://doi.org/10.5065/D6D50K46

Huffman GJ, Bolvin DT, Nelkin EJ, Wolff DB, Adler RF, Gu G et al (2007) The TRMM Multisatellite Precipitation Analysis (TMPA): quasi-global, multiyear, combined-sensor precipitation estimates at fine scales. J Hydrometeorol 8(1):38-55. https://doi.org/10.1175/jhm560.1

Intergovernmental Panel on Climate Change (IPCC) (2007). Climate change 2007 - the physical science basis: working group I contribution to the fourth assessment report of the IPCC. Science, (October 2009), 1009. https://doi.org/volume 
Intergovernmental Panel on Climate Change (IPCC) (2014) Climate change 2014: synthesis report. Contribution of Working Groups I. II and III to the fifth assessment report edited by Team CW, Pachauri RK, Meyer LA. Geneva, 151

Hoegh-Guldberg O, Jacob D, Bindi M, Brown S, Camilloni I, Diedhiou A, Hijioka Y (2018) Impacts of $1.5 \mathrm{C}$ global warming on natural and human systems. Global warming of $1.5^{\circ} \mathrm{C}$. An IPCC Special Report

Kay JE, Deser C, Phillips A, Mai A, Hannay C, Strand G, ... Vertenstein M (2015) The community earth system model (CESM) large ensemble project: a community resource for studying climate change in the presence of internal climate variability. Bull Am Meteorol Soc 96(8):1333-1349. https://doi.org/10.1175/BAMS-D-13-00255.1

Liu C, Ikeda K, Rasmussen R, Barlage M, Newman AJ, Prein AF, ... Yates D (2017) Continentalscale convection-permitting modeling of the current and future climate of North America. Clim Dyn 49(1-2):71-95. https://doi.org/10.1007/s00382-016-3327-9

Meinshausen M, Smith SJ, Calvin K, Daniel JS, Kainuma MLT, Lamarque J, . . van Vuuren DPP (2011). The RCP greenhouse gas concentrations and their extensions from 1765 to 2300 . Clim Chang 109(1-2):213. https://doi.org/10.1007/s10584-011-0156-z

National Oceanic and Atmospheric Administration (NOAA) (2019) Climate models. Retrieved September 7, 2019, from https://www.climate.gov/maps-data/primer/climate-models; website: https://www.climate.gov/maps-data/primer/climate-models

NCEP-FNL (2000) National Centers for Environmental Prediction/National Weather Service/ NOAA/U.S. Department of Commerce (2000) updated daily. NCEP FNL Operational Model Global Tropospheric Analyses, continuing from July 1999. Research Data Archive at the National Center

Nicholson SE (2013) The West African Sahel: A review of recent studies on the rainfall regime and its interannual variability. ISRN Meteorology 2013

Prein AF, Gobiet A, Suklitsch M, Truhetz H, Awan NK, Keuler K, Georgievski G (2013) Added value of convection permitting seasonal simulations. Clim Dyn 41:2655-2677. https://doi.org/ 10.1007/s00382-013-1744-6

Riahi K, Rao S, Krey V, Cho C, Chirkov V, Fischer G et al (2011) RCP 8.5-a scenario of comparatively high greenhouse gas emissions. Clim Change 109(1-2):33. https://oi.org/ 10.1007/s10584-011-0149-y

Schmidli J, Frei C, Vidale PL (2006) Downscaling from GCM precipitation: a benchmark for dynamical and statistical downscaling methods. Int J Climatol 26(5):679-689. https://doi.org/ $10.1002 /$ joc. 1287

Sylla MB, Giorgi F, Coppola E, Mariotti L (2013) Uncertainties in daily rainfall over Africa: assessment of gridded observation products and evaluation of a regional climate model simulation. Int J Climatol 33(7):1805-1817. https://doi.org/10.1002/joc.3551

Wild M, Ohmura A, Gilgen H, Roeckner E (1995) Regional climate simulation with a high resolution GCM: surface radiative fluxes. Clim Dyn 11(8):469-486. https://doi.org/10.1007/ BF00207196

Open Access This chapter is licensed under the terms of the Creative Commons Attribution 4.0 International License (http://creativecommons.org/licenses/by/4.0/), which permits use, sharing, adaptation, distribution and reproduction in any medium or format, as long as you give appropriate credit to the original author(s) and the source, provide a link to the Creative Commons license and indicate if changes were made.

The images or other third party material in this chapter are included in the chapter's Creative Commons license, unless indicated otherwise in a credit line to the material. If material is not included in the chapter's Creative Commons license and your intended use is not permitted by statutory regulation or exceeds the permitted use, you will need to obtain permission directly from the copyright holder. 